\title{
Multiphoton Ionization of Uracil at 355 nm
}

\author{
E. PRIETO ${ }^{1}$, A. GUERRERO ${ }^{1}$, D. MARTÍNEZ ${ }^{1}$, I. ÁLVAREZ ${ }^{1}$, \\ AND C. CISNEROS ${ }^{1 *}$ \\ ${ }^{1}$ Instituto de Ciencias Físicas-UNAM, Av. Universidad 1001, Chamilpa, 62210 \\ Cuernavaca, Mor.
}

*Email: carmen@fis.unam.mx

Published online: August 07, 2017

The Author(s) 2017. This article is published with open access at www .chitkara.edu. in/publications

\begin{abstract}
We present the experimental results from ionization and dissociation by multiphoton absorption (MPI) of uracil and a mixture of uracil with Ar using a Reflectron time of flight spectrometer along with radiation from $355 \mathrm{~nm}$ at pulsed Nd:YAG laser. We focus on the light ions production. The MPI mass spectra show that the presence and intensity of the resulting ions depend on the density power of the laser. The resulting ions in the mass spectra are identified and found similar behavior in the case of $\mathrm{H}^{+}$and $\mathrm{C}^{+}$as when multiple charged ions are used. Different results were found in contrast with those, recently reported, when electrons or photons of other wavelength were used. The number of $355 \mathrm{~nm}$ absorbed photons was calculated accordingly to Keldysh theory and similar results were fond using pure uracil or uracil-Ar mixture. Our results are compared with those obtained in other laboratories under different experimental conditions, some of them show only partial agreement and differences are discussed.
\end{abstract}

Keywords: Uracil, Multiphoton, Dissociation

\section{INTRODUCTION}

Uracil is one of the four nitrogen bases that belong to RNA and is one of the building blocks of RNA. The last years special interest has been concentrated on the study of the effects under UV radiation in nucleic acids also it has been considered the role that this molecule could have played in the origin and development of life on our planet [1-3]. Although aspects of astrochemical, medical or biological are of great interest, the objective of the present study is the radiation effects on the uracil molecules, processes of dissociation and ionization. Recently, it was shown that radiation can produce secondary ions/ fragments with kinetic energies from thermal up to several hundred $\mathrm{eV}$ in a

Journal of Nuclear

Physics, Material

Sciences, Radiation and

Applications

Vol-5 No-1

August 2017 pp. $35-43$ 
Prieto, E. Guerrero, A. Martínez, D. Álvarez, I. Cisneros, $\mathrm{C}$.

biological medium, and in the subsequent scattering events these energetic ions/fragments can also cause severe damage to DNA [3-4].

The Monte Carlo simulations for radiation damage studies on DNA and RNA [6], account for ionization. However, the probability of simultaneous ionization and dissociation and high energy deposition (known as dissociative ionization) has not been considered in these simulations, mainly due to lack of data until very recently [7]. In particular processes of dissociation and ionization are useful to study possible different molecular mechanisms caused by the $355 \mathrm{~nm}$ laser radiation. Most of the available experimental data by the interaction with electrons, photons from laser are in the range of 220$290 \mathrm{~nm}$ [8-9], synchrotron light of energy from 6 to $22 \mathrm{eV}$ [10] and 260nm [11] or multiple charged ions [4]. In the present study, the photodissociation and photoionization of uracil in the multiple photon absorption regimes were investigated at the wavelength of $355 \mathrm{~nm}$ and intensities of radiation in the range $10^{8}$ to $10^{9} \mathrm{~W} \cdot \mathrm{cm}^{-2}$. Radiation interacts with a cooled molecular beam of uracil or Ar-uracil mixture produced by the adiabatic expansion of vapors into a high vacuum chamber at $10^{-8}$ torr. The resulting ions were analyzed using a home-assembled Jordan R-TOF mass analyzer. On the basis of the detected ions at $355 \mathrm{~nm}$, the processes were identified as a Dissociation-Ionization. The number of photons required to form a ion was calculated accordingly with the Keldysh approximation [12] and is reported in the Multiphoton Ionization Spectra (MPI). The MPI show that the presence and intensity of the ions depends on the density power as well as the wavelength and the fact of the use Ar as carrier gas. The results are compared with those obtained in other laboratories under different experimental conditions [8-10]. This work gives new insights on behavior of the uracil molecules when they interact with photons and the products that can emerge as result of photoionization and photodissociation, as the well as the dependence of the amount or ions produced when Ar is used as carrier gas in contrast of when pure uracil is used.

\section{EXPERIMENTAL}

The photofragment spectra for uracil multiphoton absorption were obtained by a high resolution time of flight mass spectrometer, Reflectron (R-TOF) figure 1. The Reflectron is a commercial spectrometer (Jordan) modified in the laboratory [13], coupled to a vacuum chamber $60 \mathrm{~cm}$ diameter, housing the interaction zone to produce the fragment ions. A sample of uracil (SigmaAldrich, purity $\sim 99 \%$ ) was introduced by pulsed valve, pure or seeded with $\mathrm{Ar}$, into the ionization chamber in gas phase. The pulse valve has an extension with a conical tip termination inside the chamber that allows the adiabatic gas 


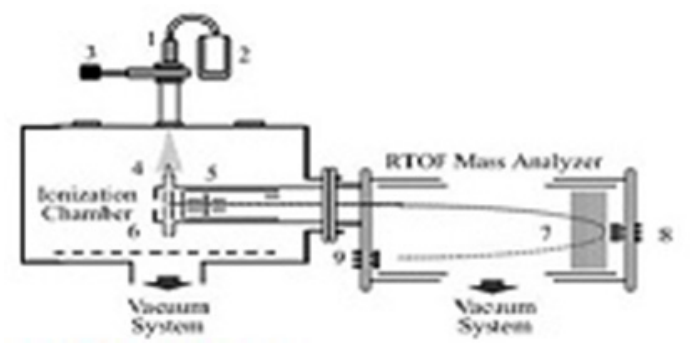

Multiphoton

Ionization of Uracil

at $355 \mathrm{~nm}$

1. Pulsed valve, 2. Sample reservoir, 3. Valve, 4. Skimmer, 5. Electrostatic lenses, 6. Extraction and acceleration plates, 7. RTOF Electrostatic lenses, 8.9 Detectors

Figure 1. Experimental setup

expansion closer to the skimmer for the generation of the supersonic molecular beam. A cooled molecular beam of uracil or with uracil/Ar was produced by adiabatic expansion in a high-vacuum chamber at $2 \times 10^{-8}$ torr. To sublimate the uracil sample, a controlled coiled resistive heater in the reservoir was used, the temperature was monitored and held at $110^{\circ} \mathrm{C}$. The pulsed valve was synchronously coupled with the laser pulses with an opening time of $250 \mu \mathrm{s}$ to ensure that the uracil molecules and laser light coincide at the center of the interaction zone. The operating pressure was $2 \times 10^{-6}$ torr. The $355 \mathrm{~nm}$ laser radiation was produced from the third harmonic of a Nd:YAG laser (Spectra Physics), operating at $30 \mathrm{~Hz}$ repetition rate. The temporal laser pulse width is $5.5 \mathrm{~ns}$ and the energies per pulse from 1 to $30 \mathrm{~mJ}$.

The laser radiation (with a Gaussian profile and vertically polarized) was focused into the interaction region using a $15 \mathrm{~cm}$ focal length lens. The diameter at the focal point was $\sim 80.0 \mu \mathrm{m}$. Under these experimental conditions, radiation intensities between $10^{9}$ and $10^{10} \mathrm{~W} \cdot \mathrm{cm}^{-2}$ were achieved. The cooled molecular beam interacted orthogonally with the laser radiation at a point located between two parallel plates continuously polarized at $5.0 \mathrm{KeV}$ and $4.5 \mathrm{KeV}$, corresponding to the extraction and the acceleration potentials, respectively.

The distance between the plates was $0.6 \mathrm{~cm}$. Holes of $10 \mathrm{~mm}$ diameter at the center of each plate with a fine metal mesh were used to extract the positively charged ions from the interaction region. The ions were driven along the field-free region of the Reflectron and eventually reached a dual Chevron microchannel plate detector after they were refocused. The ions arrived to the detector, according to the ratio charge/masses $(\mathrm{e} / \mathrm{m})$. The resolution achived was of the order of 1000. The current signal was pre-amplified, voltageconverted, digitized and sampled in time using a picosecond time analyzer from EG\&G Ortec. 
Prieto, E.

Guerrero, A. Martínez, D. Álvarez, I.

Cisneros, $\mathrm{C}$.

\section{RESULTS AND DISCUSSION}

Uracil molecules were multi-photon ionized at the wavelength of $355 \mathrm{~nm}$ with fluence between $10^{8}-10^{9} \mathrm{~W} \mathrm{~cm}^{-2}$. That corresponds to the multiphoton absorption regime accordingly to the Keldysh theory [12,14], since $\gamma$ is $>>1$. Also from Keldysh theory the relation between the ion counts per pulse (I), the laser pulse energy (E) and the photon order $(\alpha)$, the number of photons involved is $I=c E^{\alpha}$, where $\mathrm{c}$ is a constant. We measured the ion yields for the most prominent ions and calculated the number of photons involved, the results are displayed in the Table [1].

Table 1: Number of calculated photons

Photon order

\begin{tabular}{ccc}
\hline $\mathbf{m} / \mathbf{z}$ & Argon & Without Ar \\
\hline 1 & 2.04 & 1.90 \\
12 & 1.09 & 0.89 \\
13 & 2.02 & 1.75 \\
14 & 1.99 & 1.88 \\
15 & 1.99 & 2,07 \\
17 & 3.54 & 3,14 \\
18 & 3.36 & 2.21 \\
24 & 1.36 & 1.17 \\
25 & 1,56 & 1,17 \\
26 & 1.44 & 1,08 \\
27 & 1.01 & 0.68 \\
28 & 1,67 & 1,43 \\
29 & 1.89 & 1.46 \\
30 & 1,62 & 1.31 \\
\hline
\end{tabular}

As it is shown the values are slightly higher for the case where Ar is used in conjunction with uracil. Figure [2] shows the case for $\mathrm{m} / \mathrm{z}=28, \mathrm{CH}_{2} \mathrm{~N}^{+}$. Overall uncertainty is estimated as $20 \%$

Furthermore, the corresponding energies calculated from the number of photons reported in [8] for $\mathrm{m} / \mathrm{z}=28,14$ y 12 are higher, especially for the case of $\mathrm{m} / \mathrm{z}=12, \mathrm{C}^{+}$, where the result is three times higher than in our measurements. This fact deserves further investigation. It can be interpreted as in this process, a transition to an excited molecular orbital becomes saturated in such way that a small number of photons can ionize the highly excited state. 


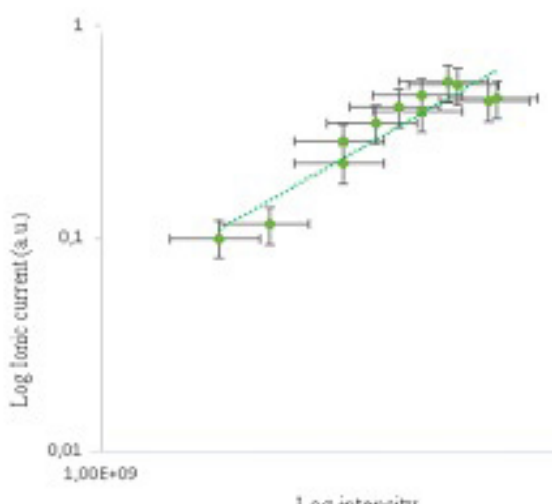

Multiphoton Ionization of Uracil at $355 \mathrm{~nm}$

Figure 2: Power dependence of $\mathrm{CH}_{2} \mathrm{~N}^{+}$from MFI on laser intensity

The shapes and photon fluence dependence do not suggest that the resulting ions are produced by a different pathways from other experiments apart from, J. DeVries [4].

Table [2] presents the relative intensities of the $\mathrm{m} / \mathrm{z}$ peaks taken from a ratio of each individual intensity to the $95 \%$ of the total ion current in uracil and Ar-uracil spectrum, at $280 \mathrm{~mW}$. In Fig [3] a comparison of MPI mass spectra for the cases with and without of Ar, it seems that the Ar makes the ions number to be slightly lower.

Table 2: Relative intensity for diferent $\mathrm{m} / \mathrm{z}$ ions

\begin{tabular}{ccc}
\multicolumn{3}{c}{ Relative intensity } \\
\hline $\mathbf{k m}$ & w/Argon & Without Argon \\
\hline 1 & 13,47 & 14,51 \\
12 & 31,60 & 29,26 \\
13 & 5,69 & 5,87 \\
14 & 2,93 & 3,03 \\
15 & 5,67 & 6,18 \\
18 & 3,19 & 2,54 \\
24 & 12,60 & 12,93 \\
25 & 5,00 & 4,86 \\
26 & 7,26 & 7,57 \\
27 & 1,90 & 2,14 \\
28 & 1,22 & 1,39 \\
29 & 4,88 & 4,80 \\
\hline
\end{tabular}


Prieto, E.

Guerrero, A.

Martínez, D.

Álvarez, I.

Cisneros, $\mathrm{C}$.

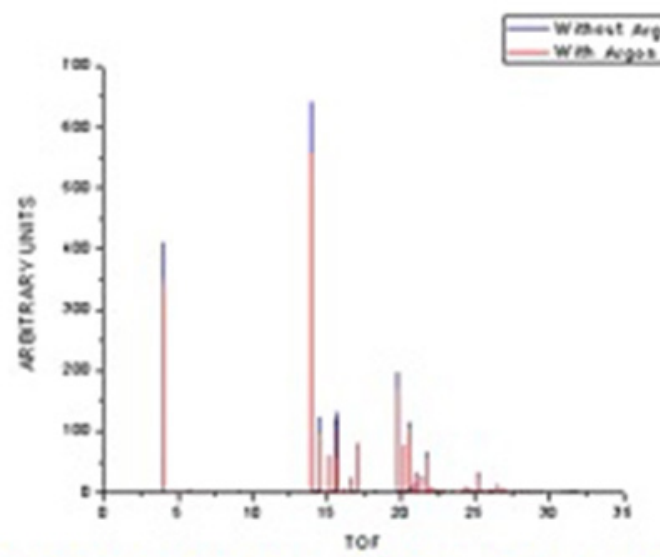

Figure 3: Comparison of time of fight spectra for the interaction of $280 \mathrm{~W} / \mathrm{cm}^{2}$ with pure uracil and uracil-Ar mixture.

The most import and interesting feature in the present measurements is the different structure of the our TOF spectra. Small ions prevail with maximum intensities of $\mathrm{H}^{+}$and $\mathrm{C}^{+}$only observed in experiments with ionization using highly charged ions $\left(\mathrm{Xe}^{\mathrm{q}+} \mathrm{q}=5-25\right)[4]$ Figure [3].

From the ions observed, the fragmentation process corresponds to a ladder switching mechanism. The fragmentation of parent ion, not detected in the present study, can give rise $\mathrm{m} / \mathrm{z}=69$ ion, $\mathrm{C}_{3} \mathrm{H}_{3} \mathrm{NO}^{+}$, reported in [10], which in turn it can lose $\mathrm{H}_{2} \mathrm{O}$ producing the $\mathrm{m} / \mathrm{z}=51$ ion, $\mathrm{C}_{3} \mathrm{HN}^{+}$. This ion was reported for first time in electron experiments $[15,17]$ using electrons and Ar ions as projectiles [16]. The ion $\mathrm{m} / \mathrm{z}=45$ has not been reported, it is suggested corresponds to $\mathrm{CO}_{2} \mathrm{H}^{+}$or $\mathrm{CH}_{3} \mathrm{NO}^{+}$ions. With regard to the ion of $\mathrm{m} / \mathrm{z}=43, \mathrm{HNCO}^{+}$, it is produced along with the fragment $\mathrm{m} / \mathrm{z}=69$ which in turn dissociates as $\mathrm{m} / \mathrm{z}=41, \mathrm{HC}_{2} \mathrm{O}^{+}$. Other fragmentation pathway of $\mathrm{m} / \mathrm{z}=69$ leads to the formation of $\mathrm{m} / \mathrm{z}=28, \mathrm{HCNH}^{+}$. The ion $\mathrm{m} / \mathrm{z}=29$, corresponds to $\mathrm{N}_{2} \mathrm{H}^{+} \mathrm{HCO}^{+}$or $\mathrm{CH}_{3} \mathrm{~N}^{+}$. A deuterated ion comparison supports to the last one. The $\mathrm{m} / \mathrm{z}=27$ could be $\mathrm{C}_{2} \mathrm{H}_{3}{ }^{+}$or $\mathrm{HCN}^{+}$, Reflectron impact experiments suggest $\mathrm{HCN}^{+}$. For $\mathrm{m} / \mathrm{z}=26$ : $\mathrm{C}_{2} \mathrm{H}_{2}$ [10], it was interpreted as formed via loss of $2 \mathrm{HNCO}$ molecules directly from the parent ion, a not ladder switching mechanism. As in [10] we assign $\mathrm{m} / \mathrm{z}=18, \mathrm{H}_{2} \mathrm{O}^{+}, \mathrm{m} / \mathrm{z}$ $=17, \mathrm{NH}_{3}^{+}, \mathrm{m} / \mathrm{z}=16, \mathrm{O}^{+}, \mathrm{m} / \mathrm{z}=15: \mathrm{NH}^{+}$, not reported before. The ions $\mathrm{m} / \mathrm{z}=14: \mathrm{N}^{+}, \mathrm{m} / \mathrm{z}=12: \mathrm{C}^{+}, \mathrm{m} / \mathrm{z}=1: \mathrm{H}^{+}$, have been reported in [4]. The ratio of intensities of peaks $\mathrm{m} / \mathrm{z}=12$ and 1 agree better with Ref [4,]. Coupier, B., [18], measured both using proton and electron impact and discussed the structure of the various of the ions observed, such as $\mathrm{m} / \mathrm{z}=69,42,29$ and 28 . Appearance Energies (AE) for certain of the ions detected have been already 
published and they have been used mainly to propose different dissociation pathways in some cases to justified the appearance of such ions [10].

Unfortunately, although computational work can simulate quite accurately the behavior of molecules such as uracil, fully $a b$ initio simulations of molecular photodynamics are far beyond reach even for the most advanced supercomputers. This makes the need of experimental more crucial since still there are several open questions to answer related to uracil photodissociation.

Table 3: is the summary of different TOF data for uracil along with that obtained in the present experiment.

\begin{tabular}{|c|c|c|c|c|c|c|}
\hline \multicolumn{2}{|c|}{ Present work } & \multirow{2}{*}{$\begin{array}{c}\text { Riszka } \\
\text { et al. }\end{array}$} & \multirow{2}{*}{\multicolumn{2}{|c|}{ Bare et al. Iinhoff etal. }} & \multirow{2}{*}{$\begin{array}{l}\text { Rice } \\
\text { et al. }\end{array}$} & \multirow[t]{2}{*}{ Jochims et. } \\
\hline ion & & & & & & \\
\hline $\mathrm{H}^{+}$ & 1 & $\ldots$ & 1 & 1 & $\ldots$ & $\ldots$ \\
\hline $\mathrm{H}_{2}^{+}$ & 2 & $\ldots$. & $\ldots$. & 2 & $\ldots$ & $\ldots$. \\
\hline $\mathrm{C}^{+}$ & 12 & 12 & 12 & 12 & $\ldots$ & $\ldots$. \\
\hline $\mathrm{CH}^{+}$ & 13 & 13 & 13 & 13 & $\ldots$ & $\ldots$. \\
\hline $\mathrm{N}^{+}, \mathrm{CH}_{2}^{+}$ & 14 & 14 & 14 & 14 & $\ldots$ & 14 \\
\hline $\mathrm{CH}_{3}^{+}$ & 15 & $\ldots$. & 15 & 15 & $\ldots$ & $\ldots$. \\
\hline $\mathrm{O}^{+}, \mathrm{NH}_{2}^{+}$ & 16 & $\ldots$ & $\ldots$. & 16 & $\ldots$ & $\ldots$. \\
\hline $\mathrm{NH}_{3}^{+}, \mathrm{OH}^{+}$ & 17 & & $\cdots$ & 17 & $\cdots$ & 17 \\
\hline $\mathrm{H}_{2} \mathrm{O}^{+}$ & 18 & & $\ldots$. & 18 & $\ldots$ & 18 \\
\hline $\mathrm{C}_{2}^{+}$ & 24 & 24 & 24 & 24 & $\ldots$ & $\ldots$. \\
\hline $\mathrm{C}_{2} \mathrm{H}^{+}$ & 25 & & 25 & 25 & $\ldots$ & $\ldots$. \\
\hline $\mathrm{C}_{2} \mathrm{H}_{2}^{+}, \mathrm{CN}^{+}$ & 26 & 26 & 26 & 26 & 26 & 26 \\
\hline $\mathrm{CNH}^{+}$ & 27 & 27 & 27 & 27 & 27 & 27 \\
\hline $\mathrm{NHCH}^{+}, \mathrm{CO}^{+}$ & 28 & 28 & 28 & 28 & 28 & 28 \\
\hline $\mathrm{HNCH}_{2}^{+}$ & 29 & 29 & 29 & 29 & 29 & 29 \\
\hline $\mathrm{NO}^{+}, \mathrm{H}_{2} \mathrm{CO}^{+}$ & 30 & $\ldots$ & $\ldots$ & 30 & $\ldots$ & $\ldots$. \\
\hline $\mathrm{COH}_{3}^{+}, \mathrm{NOH}^{+}$ & 31 & $\ldots$ & $\cdots$ & $\ldots$ & $\cdots$ & $\ldots$. \\
\hline $\mathrm{NOH}_{2}^{+}$ & 32 & $\ldots$. & $\ldots$ & $\ldots$. & $\ldots$ & $\ldots$. \\
\hline $\mathrm{C}_{3}^{+}$ & 36 & $\ldots$. & $\ldots$. & $\ldots$. & $\ldots$ & $\ldots$. \\
\hline $\mathrm{C}_{3} \mathrm{H}^{+}$ & 37 & $\ldots$ & $\cdots$ & $\ldots$ & $\ldots$ & $\ldots$ \\
\hline $\mathrm{C}_{2} \mathrm{~N}^{+}$ & 38 & 38 & 38 & 38 & 38 & $\ldots$ \\
\hline $\mathrm{C}_{2} \mathrm{NH}^{+}$ & 39 & 39 & 39 & 39 & 39 & 39 \\
\hline $\mathrm{C}_{2} \mathrm{NH}_{2}^{+}$ & 40 & 40 & 40 & 40 & 40 & 40 \\
\hline
\end{tabular}


Prieto, E.

Guerrero, A.

Martínez, D.

Álvarez, I.

Cisneros, $\mathrm{C}$.

\begin{tabular}{ccccccc}
\hline $\mathrm{C}_{2} \mathrm{NH}_{3}^{+}$ & 41 & 41 & 41 & 41 & 41 & 11 \\
$\mathrm{C}_{2} \mathrm{H}_{2} \mathrm{O}^{+}$ & 42 & 42 & 42 & 42 & 42 & 42 \\
$\mathrm{HNCO}^{+}$ & 43 & 43 & 43 & 43 & 43 & 43 \\
$\mathrm{CO}_{2}^{+}, \mathrm{CH}_{2} \mathrm{NO}^{+}$ & 44 & 44 & 44 & 44 & 44 & 44 \\
$\mathrm{CO}_{2} \mathrm{H}^{+}$, & 45 & $\ldots$. & $\ldots$ & $\ldots$. & $\ldots$. & $\ldots$. \\
$\mathrm{CH}_{3} \mathrm{NO}^{+}$ & & & $\ldots$ & 51 & 51 & $\ldots$. \\
$\mathrm{C}_{3} \mathrm{HN}^{+}$ & 51 & $\ldots$ & $\ldots$ & 5 & & \\
\hline
\end{tabular}

Ryszka[9], Barck[8], Imhoff[16], Rice[17] Jochims[10]

\section{CONCLUSIONS}

Multiphoton studies are an excellent tool to address the main process that take place when photons interact with neutral species. In the present work, it is reported the analysis of photodissociation of uracil and uracil seeded with Ar gas using laser radiation of $355 \mathrm{~nm}$ in a cooled molecular beam. TOF-MS spectra are presented. Table 3 is the summary of different TOF data for uracil along with that obtained in the present experiment

At $355 \mathrm{~nm}$, photon absorption is followed by a D-I. Some new dissociation channels were proposed based on cations detected, the assignment of the $\mathrm{m} / \mathrm{z}$ peaks in our MPI absorption spectra are mostly based on previous data. We have focused in the range of low $\mathrm{m} / \mathrm{z}$ regime, our results are different from the ones found when electrons or photons of different energies were employed, mainly with respect to the $\mathrm{H}^{+}$and $\mathrm{C}^{+}$production. With regard to those ions, our results are like those found from the interaction with highly charged ions. MPI was found similar with and without Ar as carrier gas. For low mass ions the number of absorbed photons was calculated accordingly to the Keldysh theory in order to compare them with some theoretical results. However, are necessary more experiments and calculations to provide a deeper understanding of the uracil photodissociation.

\section{ACKNOWLEDGMENTS}

This work was financial supported by the projects PAPIIT-UNAM, IN101215 and IN102516.

\section{REFERENCES}

[1] Conconi, A., \& Bell, B.(2017) Molecular biology: The long and short of a DNAdamage response, doi:10.1038/nature 22488 
[2] Kuzicheva, E.A.,\& Simakov, M.B. (1999) Advances in Space Research 23 (2), 391.

[3] Joyce, G.F. (2002) The antiquity of RNA-based evolution,doi: 10.1038/418214a

Multiphoton

Ionization of Uracil

at $355 \mathrm{~nm}$

[4] de Vries J., Hoekstra, R. Morgenstern, R. \& Schlatholter T, (2003) Charge Driven Fragmentation of Nucleobases, doi.org/10.1103/PhysRevLett.91.053401

[5] Schlatholter, T. Hoekstra R, Zamith, S. Ni, Y. Muller, H.G et al , (2005) Response of Polyatomic Molecules to Ultrastrong Laser- and Ion-Induced Fields, doi: 10.1103/PhysRevLett.94.233001

[6] Nikjoo, H.L., Charlton, D.E., \& Goodhead, D.T.,(1994) Monte Carlo track structure studies of energy deposition and calculation of initial DSB and RBE, doi.org/10.1016/0273-1177(94)90466-1

[7] Sadr, L., Mignon P., Hassan, A., Carime, A., Bernadette, B., et al (2012) DFT study of the fragmentation mechanism of uracil RNA base, doi: 10.1039/ c2cp40384f

[8] Barc, B., Ryszka, M., Spurrell, J., Dampc, M., Limão-Vieira, P.,et al . (2013) Multi-photon ionization and fragmentation of uracil: Neutral excited-state ring opening and hydration effects, doi.org/10.1063/1.4851476

[9] Ryszka, M., Pandey, R., Rizk, C., Tabet, J., Barc, B.,et al (2016)Dissociative multi-photon ionization of isolated uracil and uracil-adenine complexes, doi.org /10.1016/j.ijms.2015.12.006

[10] Jochims , H-W., Schwell , H., Baumgartel , S., \& Leach M., (2005) Photoion mass spectrometry of adenine, thymine and uracil in the $6-22 \mathrm{eV}$ photon energy range, doi:10.1016/j.chemphys.2005.03.008

[11] Bolognesi, P., O’Keeffe, P..Mazza, T., Bozek, J., Coffee, R. et al . (2015) A study of the dynamical energy flow in uracil ,doi:10.1088/1742-6596/635/11/112062

[12] Keldysh, L.V., (1965) Sov. Ionization in the field of a strong electromagnetic wave Soviet Physics JETP 20 (5), 1307-1314

[13] Poveda, J. C., Guerrero, A., Cisneros, C., \& Alvarez I., (2015) Carbon/hydrogen clusters $\left[\mathrm{CnHx}^{+}\right]$formation from laser irradiation of coronene, doi:10.1088/1742$6596 / 605 / 1 / 012021$

[14] Nam, H. S. H., Park, S., Song, J. K., \& Park, J. S. M., (2007) Photoinduced Dynamics of Hydrated Adenine Clusters, doi: 10.1021/jp067193i

[15] Hecht, S.M.,Gupta,A.S. \& Leonard, N.J.(1969)Position of uridine thiation: The identification of minor nucleosides from transfer RNA by mass spectrometry doi. org/10.1016/0005-2787(69)90195-6

[16] Imhoff, M., Deng, Z.,\& Huels, M. A.(2007)Ionizing fragmentation of uracil and 5-bromouracil by electron impact in gas phase and hyperthermal $\mathrm{Ar}^{+}$ion irradiation in condensed phase doi:10.1016/j.ijms.2006.11.004

[17] Rice, J. M., Dudek, G.O., \& Barber M. (1965) Mass Spectra of Nucleic Acid Derivatives. Pyrimidines, doi: 10.1021/ja00948a029

[18] Coupier, B., Farizon, B., Farizon, M. et al. (2002) 20: 459. doi:10.1140/epjd/ e2002-00166-3 